\title{
Intimate partner violence and nutritional status among nepalese women: an investigation of associations
}

\author{
Ramesh P. Adhikari ${ }^{1 *}$ D, Subash Yogi ${ }^{2}$, Ajay Acharya $^{3}$ and Kenda Cunningham ${ }^{1,4}$
}

\begin{abstract}
Background: Malnutrition among women in Nepal persists as a major public health burden. Global literature suggests that domestic violence may have a negative impact on women's nutritional status. The contribution of intimate partner violence (IPV) to increased stress levels, poor self-care including the consumption of less food and, in turn, malnutrition has been documented. However, there is little empirical evidence on IPV and its relationship with women's nutritional status in Nepal and thus, this paper assesses these associations.

Methods: We used data on non-pregnant married women $(n=3293)$ from the 2016 Nepal Demographic and Health Survey (NDHS). The primary exposure variable was whether the women had ever experienced physical, sexual, or emotional violence or controlling behaviours by a current or former partner, based on her responses to the NDHS domestic violence questions. The primary outcome variables were three indicators of malnutrition: under-weight (BMI < 18.5), over-weight (BMI $\geq 25)$, and anemia $(\mathrm{Hb}<11.0 \mathrm{~g} \mathrm{dL})$. We used logistic and multinomial regression models, adjusted for potential socio-demographic and economic confounders, as well as clustering, to examine associations between IPV exposure and malnutrition.
\end{abstract}

Results: Approximately 44\% of women had experienced at least one of the four types of IPV. Among them, around $16,25 \%$. and $44 \%$ were underweight, overweight, or anemic, respectively, compared to 13,29 , and $35 \%$ of women never exposed to IPV. We did not find any associations between underweight and any of the four types of IPV. Overweight was associated with physical violence (adjusted $\mathrm{RRR}=0.67, \mathrm{P}<0.01, \mathrm{Cl}=0.50-0.88$ ) and severe physical violence (adjusted RRR $=0.53, P<0.05, \mathrm{Cl}=0.32-0.88$ ) Controlling behaviors were associated with anemia (adjusted $\mathrm{RRR}=1.31, P<0.01, \mathrm{Cl}=1.11-1.54)$.

Conclusions: Among married Nepalese women, physical violence appears to be a risk factor for one's weight and controlling behaviors for one's anemia status. Additional, rigorous, mixed-methods research is needed to understand the reporting of IPV and what relationships do or do not exist between IPV experience and nutrition both in Nepal and in other settings.

Keywords: Intimate partner violence, Nutrition, Underweight, Anemia, Nepal

\footnotetext{
* Correspondence: rameshadhikaria@gmail.com

${ }^{1}$ Suaahara II, Helen Keller International Nepal, Patan, Lalitpur, Nepal

Full list of author information is available at the end of the article
}

(C) The Author(s). 2020 Open Access This article is licensed under a Creative Commons Attribution 4.0 International License, which permits use, sharing, adaptation, distribution and reproduction in any medium or format, as long as you give appropriate credit to the original author(s) and the source, provide a link to the Creative Commons licence, and indicate if changes were made. The images or other third party material in this article are included in the article's Creative Commons licence, unless indicated otherwise in a credit line to the material. If material is not included in the article's Creative Commons licence and your intended use is not permitted by statutory regulation or exceeds the permitted use, you will need to obtain permission directly from the copyright holder. To view a copy of this licence, visit http://creativecommons.org/licenses/by/4.0/ The Creative Commons Public Domain Dedication waiver (http://creativecommons.org/publicdomain/zero/1.0/) applies to the data made available in this article, unless otherwise stated in a credit line to the data. 


\section{Background}

Intimate partner violence (IPV) against women is increasingly recognized as a public health concern as it has several consequences on women's physical and psychosocial wellbeing. IPV includes physical, sexual, and emotional violence by a current or former partner. Global estimates show that around $30 \%$ of women who have been in a relationship have experienced violence by an intimate partner, with exposure to IPV relatively higher (38\%) in South-East Asia than other regions of the world [1]. Similarly, a survey conducted in 10 different countries from 2000 to 2003 showed women's exposure to IPV to ranges from 15 to $71 \%$ [2]. Associations between IPV prevalence and various household demographic and contextual factors, including socio-economic status have also been documented [3-6]. A recent study based on 42 demographic and health surveys from low- and middle- income countries (LMIC), revealed that about one in three women experience IPV at some point during their life [7].

IPV has negative ramifications on women's physical and mental health; depression triggered by IPV, for example, can in turn affect a women's ability to care for herself $[1,8,9]$. Although it seems likely that IPV has an impact on the nutritional status of affected women, studies on the links between IPV and women's nutritional status, particularly in LMICs are limited [3]. Available literature suggests that experiencing violence could influence one's nutritional status in various ways. For example, IPV could increase depression and stress levels $[10,11]$ which could result in women consuming fewer or more calories and in turn, being over or underweight. IPV may also increase a woman's risk-taking behaviors (e.g. smoking, drug s or alcohol abuse) which in turn, would influence her self-care, dietary intake and nutritional status [12, 13]. An analysis using data from the 1998-1999 India family health survey showed that mothers who experience domestic violence multiple times in a year are more likely to be underweight and anemic, even after controlling for socio-economic and demographic factors [4].. A study in Bangladesh indicated that women of reproductive age (WRA) who experience physical or sexual violence are more likely to be underweight, with body mass index (BMI) less than $18.5 \mathrm{~kg} / \mathrm{m}^{2}$ after controlling for the effect of age, education, occupation and other potentially confounding factors [3]..

In Nepal, malnutrition among WRA is a serious public health: two in every five $(41 \%)$ are anemic, while $17 \%$ are underweight $\left(\mathrm{BMI}<18.5 \mathrm{~kg} / \mathrm{m}^{2}\right)$ and $22 \%$ overweight or obese (BMI $\left.>25 \mathrm{~kg} / \mathrm{m}^{2}\right)$. Prevalence rates vary by region of the country, socioeconomic status, and other factors. The 2016 Nepal
Demographic and Health Survey (NDHS) also highlighted that $26 \%$ of ever married WRA have experienced IPV at some point [14]. In Nepal, because of patriarchal norms and socio-cultural practices, women may face discrimination and even shame and social isolation if they share domestic problems and seek support from others. Thus, due to self-blame and stigma, IPV may be under reported in surveys in Nepal [1, 15-17] . There are no studies to date, however, looking at whether there's an association between experiencing IPV and nutritional status in Nepal. Therefore, this study assesses associations between IPV and women's nutritional status, including underweight, overweight/obesity, and anemia in Nepal.

\section{Methods}

This paper uses data from the 2016 NDHS, a nationally representative cross-sectional household survey. This dataset includes information on a wide variety of health topics, as well as socio-economic and demographic factors; additional information, such as women's experience with domestic violence, was collected among subsamples. The sampling details for this survey have been documented in the full NDHS report [14]. Among the 12,862 WRA included in the survey, the domestic violence module was administered to 4444 women. For this analysis, we included the 3310 women (among the 4444 women) who were ever married, but neither currently pregnant nor had given birth in the previous 2 months. Some cases were further excluded because their BMI measurement was an outlier $(N=7)$ or they had refused to have their biomarker data collected $(N=10)$. Thus, the final sample size for analyses done for this paper was $N=3293$ [14].

Three indicators of women's nutritional status were used as outcome variables: underweight (body mass index [BMI] less than 18.5), overweight/obesity (BMI of 25 or more), and anemia (hemoglobin level of less than $11 \mathrm{~g}$ per deciliter).

IPV, the primary exposure variable, was measured in two different ways based on 13 questions related to emotional, physical, and sexual violence and 5 questions related to controlling behaviours. Questions on emotional violence asked the woman if she had ever been humiliated in front of others; threatened or had someone close to her threatened with harm; or insulted or made to feel bad about herself. Questions on physical violence included asking the woman if a partner had ever pushed, shaken, or thrown something at her; slapped or twisted her arm; punched her with a fist or something that could hurt; kicked or dragged her; tried to strangle or burn her; or attacked her with a knife, gun, or other weapon or threatened to do so. Sexual 
violence questions included whether she had been forced to engage or threatened by sexual intercourse and acts. Questions related to controlling behaviours included whether she felt that her husband/partner was jealous or angry if she talked to other men; frequently accused her of being unfaithful; did not permit her to meet her female friends; tried to limit her contact with her family; or insisted on knowing where she is at all times. For the first measurement of IPV, responses to each of the 13 questions related to emotional, physical, and sexual violence and 5 questions related to controlling behaviours were combined to generate a dichotomous variable denoting "any experience of IPV including controlling behaviours " if she answered "yes" to any of the 18 questions. For the second measurement of IPV, we focused only on the 13 physical, emotional and sexual violence questions. Additionally, the severity of physical violence was measured based on none (never experienced physical violence) moderate (if a partner had ever pushed, shaken, or thrown something at her or slapped her) or severe (if the partner had ever twisted her arm or punched her with a fist or something that could hurt; kicked or dragged her; tried to strangle or burn her; or attacked her with a knife, gun, or other weapon or threatened to do so).

Potentially confounding socio-demographic and economic factors, selected based on knowledge of the local context and prior studies on nutrition and IPV in LMICs, particularly in South Asia were included in the adjusted models: the respondent woman's age in years and years of formal schooling as well as household size, caste/ethnicity (defined as Dalit, Muslim, Janajati, other terai caste, Brahmin/Chhetri, and others), wealth status (using DHS wealth quintiles), and place of residency (urban and rural).

To explore associations between IPV and malnutrition, logistic and multinomial regression models were used. We also assessed multicollinearity among the different types of IPV and then explored associations between each type of IPV and each indicator of malnutrition. The weighted sample was used to adjust for the survey design effect. To adjust for clustering, the primary sampling unit (sub-ward) was used. All data analysis was performed in Stata14.

\section{Results}

\section{Characteristics of the study population}

The median age of the married, non-pregnant women in this sample was 32 years and more than two-fifths (44\%) of the respondents had no formal schooling. Nearly one-third of the respondents belonged to the Brahmin/Chhetri caste/ethnic group and about threefifths $(60 \%)$ resided in urban areas of Nepal. Among the respondent women, around $44 \%$ reported to have experienced at least one type of IPV at some point in their life; around 14\% were underweight, $27 \%$ overweight/obese and 39\% anemic (Table 1).

\section{Bivariate analysis}

The prevalence of having ever experienced IPV was around $42-50 \%$ for each age category, but the prevalence was highest among women aged 35-39 years (49.5\%). We found a much higher prevalence of having experienced IPV among women who had no schooling $(49 \%)$ than those with the highest levels of schooling (34.3\%) $(P<0.001)$. Fewer Brahmin/Chettri women reported IPV (31\%) than any other caste/ethnicity group $(P<0.001)$. Underweight women tended to be younger $(P<0.001)$, have fewer years of schooling $(P<0.001)$, live with larger families $(P<0.001)$, and reside in rural areas $(P<0.001)$. Overweight women tended to be older $(P<0.001)$, educated with at least some formal schooling $(P<0.001)$, reside with wealthier families $(P<0.001)$ and in urban areas $(P<0.001)$. The differences among women with anemia vs. those without were not as drastic. Anemia, however, seems to be a greater problem for terai caste groups and Muslims (who are also heavily concentrated in the terai) $(P<0.001)$ (Table 2).

Among respondent women, those who had ever experienced IPV were more likely to be underweight $(16 \%$ vs. $13 \% ; P<0.05)$ and to have had anemia $(44 \%$ vs $35 \%)(P<0.001)$ compared to those who had never experienced IPV. Those who had experienced severe physical violence also had a higher prevalence of being underweight than those who had experienced moderate or no physical violence $(22 \%$ vs. $16 \%$ vs. 13\%; $P<0.001$ ) (Table 2).

\section{Multivariate analysis}

Table 3 provides the results from analyses of adjusted associations between a woman having ever experienced IPV (including and excluding controlling behaviours) and being malnourished including underweight, overweight and anemia, respectively. The adjusted multinomial logistic regression model indicated that having experienced IPV, regardless of whether the definition includes or excludes controlling behaviors, was not associated with an increased or decreased risk of being underweight or overweight. The adjusted logistic regression model results, however indicated that exposure to IPV, when including controlling behaviours in the definition, was associated with increased odds of anemia.

Some of the socio-economic and demographic factors, such as wealth were associated with one's nutritional status: women from less wealthy households had an increased risk of being underweight (RRR 0.47, CI: $0.25-0.89$ ) whereas those from wealthier households had an increased risk of being overweight 
Table 1 Socio-demographic characteristics, exposure to intimate partner violence, and nutritional status of the respondent women $(N=3293)$

Woman's age (in completed years)
$15-19$
$20-24$
$25-29$
$30-34$
$35-39$
$40-44$
$45-49$

Woman's education (by years of formal schooling)

$$
\begin{aligned}
& \text { No school } \\
& \text { 1-5 years school } \\
& 6-9 \text { years school } \\
& 10 \text { and above years } \\
& \text { Family size } \\
& \text { Less than } 5 \\
& 5 \text { and above } \\
& \text { Caste/ethnicity } \\
& \text { Dalit } \\
& \text { Muslim } \\
& \text { Janajati }
\end{aligned}
$$$$
\text { 6-9 years school }
$$$$
10 \text { and above years of school }
$$

Other terai caste

Brahmin/Chhetri

Other

Place of residence

Urban
Rural
Wealth quintile
Poorest
Second poorest
Middle
Second richest
Richest
ver experienced intimate partner violence ( $N=3293$ )
Physical violence
Emotional violence
Sexual violence
Controlling behaviours
Overall violence (excluding controlling behaviours)
Overall violence (including controlling behaviours)
Severity of physical violence ( $N=3293$ )
None
Moderate

$\%$

\section{N}

Table 1 Socio-demographic characteristics, exposure to intimate partner violence, and nutritional status of the respondent women ( $N=3293$ ) (Continued)

\begin{tabular}{lc}
\hline & $\mathrm{N}$ \\
\hline Severe & $\%$ \\
Nutritional status $(N=3293)$ & 10.0 \\
Underweight & 14.2 \\
Overweight & 27.1 \\
Anemic & 39.1 \\
\hline
\end{tabular}

(RRR 9.50, CI: 6.08-14.84). Likewise, having a lower level of education was associated with an increased risk of being underweight (RRR 0.96, CI: 0.92-0.99).

Using adjusted multinomial logistic regression models, we show results for each specific type of IPV and overweight and underweight versus anemia, respectively (Tables 4 and 5) We did not find any association between any of the 4 types of IPV and underweight. Women exposed to any physical violence had a decreased risk of being overweight/obese, but there was no association for the other 3 types of IPV. Adjusted odds ratios indicated that, only controlling behaviours and none of the other specific types of IPV were associated with an increased risk of being anemic.

Table 6 reports that we found no association between the severity of physical violence and risk of being underweight or anemic. Women exposed to severe physical violence, however, had a decreased risk of being overweight/obese.

\section{Discussion}

This paper generates evidence on associations between IPV and women's nutritional status in Nepal, based on a nationally representative data set. Around $44 \%$ of women had ever experienced emotional, physical, or sexual violence or controlling behaviours from their spouse/partner. Among the sample population, malnutrition was also a problem: $14 \%$ were underweight, $27 \%$ overweight/obese and 39\% anemic. In final, adjusted models, we found no association of IPV, regardless of whether the definition included or excluded controlling behaviours, on underweight and overweight. IPV, when defined to include controlling behaviours, however, was associated with anemia. Additionally, none of the specific types of violence was associated with being underweight, but exposure to physical IPV was associated with a decreased risk of being overweight/obese. Likewise, the severity of physical violence was not associated with being underweight but the greater the severity of physical IPV, the lower the risk of being overweight/obesity.

Some of the null findings in this study may result from women's under-reporting of IPV due to self-blame, 
Table 2 Women's nutritional status by exposure to intimate partner violence, and both by socio-demographic and economic characteristics $(N=3293)$

\begin{tabular}{|c|c|c|c|c|c|c|c|c|c|}
\hline & $\begin{array}{l}\text { Ever experienced } \\
\text { IPV (including } \\
\text { controlling } \\
\text { behaviours) }\end{array}$ & $\begin{array}{l}\boldsymbol{P} \\
\text { value }\end{array}$ & Under-weight & $\begin{array}{l}\boldsymbol{P} \\
\text { value }\end{array}$ & Over-weight & $\begin{array}{l}\boldsymbol{P} \\
\text { value }\end{array}$ & Anemic & $\begin{array}{l}P \\
\text { value }\end{array}$ & $\mathrm{N}$ \\
\hline & $\%$ & & $\%$ & & $\%$ & & $\%$ & & \\
\hline \multicolumn{10}{|l|}{$\begin{array}{l}\text { IPV (including controlling } \\
\text { behaviours) }\end{array}$} \\
\hline Yes & & & 15.9 & 0.042 & 24.6 & 0.055 & 44.0 & $<0.001$ & 1442 \\
\hline No & & & 13.0 & & 29.1 & & 35.3 & & 1851 \\
\hline \multicolumn{10}{|c|}{ IPV (excluding controlling behaviours) } \\
\hline Yes & & & 18.1 & 0.001 & 21.5 & 0.002 & 44.1 & 0.011 & 869 \\
\hline No & & & 12.9 & & 29.2 & & 37.3 & & 2424 \\
\hline \multicolumn{10}{|l|}{ Types of violence } \\
\hline \multicolumn{10}{|l|}{ Physical violence } \\
\hline Yes & & & 18.6 & $<0.001$ & 19.1 & $<0.001$ & 44.4 & 0.009 & 757 \\
\hline No & & & 12.9 & & 29.6 & & 37.5 & & 2536 \\
\hline \multicolumn{10}{|l|}{ Emotional violence } \\
\hline Yes & & & 18.7 & 0.011 & 25.1 & 0.502 & 39.0 & 0.965 & 402 \\
\hline No & & & 13.6 & & 27.4 & & 39.1 & & 2891 \\
\hline \multicolumn{10}{|l|}{ Sexual violence } \\
\hline Yes & & & 18.6 & 0.065 & 23.5 & 0.270 & 45.3 & 0.081 & 231 \\
\hline No & & & 13.9 & & 27.4 & & 38.6 & & 3062 \\
\hline \multicolumn{10}{|l|}{ Controlling behaviours } \\
\hline Yes & & & 16.1 & 0.052 & 24.9 & 0.152 & 44.8 & $<0.001$ & 1110 \\
\hline No & & & 13.3 & & 28.3 & & 36.2 & & 2183 \\
\hline \multicolumn{10}{|l|}{ Severity of physical violence } \\
\hline None & & & 12.9 & & 29.5 & & 37.5 & & 2536 \\
\hline Moderate & & & 15.9 & $<0.001$ & 21.7 & $<0.001$ & 45.9 & 0.033 & 428 \\
\hline Severe & & & 22.1 & & 15.8 & & 42.4 & & 329 \\
\hline \multicolumn{10}{|l|}{ Woman's age (in completed years) } \\
\hline $15-19$ & 44.6 & 0.230 & 26.8 & $<0.001$ & 4.7 & $<0.001$ & 40.5 & 0.790 & 170 \\
\hline $20-24$ & 42.3 & & 18.8 & & 14.1 & & 41.7 & & 512 \\
\hline $25-29$ & 44.7 & & 15.3 & & 26.0 & & 40.2 & & 601 \\
\hline $30-34$ & 42.5 & & 10.6 & & 34.2 & & 39.6 & & 613 \\
\hline $35-39$ & 49.5 & & 9.3 & & 31.4 & & 38.1 & & 579 \\
\hline $40-44$ & 40.0 & & 16.2 & & 30.2 & & 37.6 & & 481 \\
\hline $45-49$ & 41.6 & & 11.4 & & 35.8 & & 35.4 & & 336 \\
\hline \multicolumn{10}{|c|}{ Woman's education (by years of formal schooling) } \\
\hline No school & 49.0 & $<0.001$ & 18.9 & $<0.001$ & 19.9 & $<0.001$ & 41.1 & 0.498 & 1458 \\
\hline $1-5$ years of school & 46.8 & & 12.5 & & 32.2 & & 38.3 & & 568 \\
\hline $6-9$ years of school & 38.0 & & 10.3 & & 31.8 & & 37.5 & & 678 \\
\hline 10 and above years of school & 34.3 & & 9.0 & & 35.0 & & 36.7 & & 589 \\
\hline \multicolumn{10}{|l|}{ Family size } \\
\hline Less than 5 & 42.8 & 0.431 & 9.8 & $<0.001$ & 31.5 & $<0.001$ & 36.4 & $<0.05$ & 1473 \\
\hline 5 and above & 44.5 & & 17.9 & & 23.6 & & 41.3 & & 1820 \\
\hline
\end{tabular}


Table 2 Women's nutritional status by exposure to intimate partner violence, and both by socio-demographic and economic characteristics $(N=3293)$ (Continued)

\begin{tabular}{|c|c|c|c|c|c|c|c|c|c|}
\hline & $\begin{array}{l}\text { Ever experienced } \\
\text { IPV (including } \\
\text { controlling } \\
\text { behaviours) }\end{array}$ & $\begin{array}{l}\boldsymbol{P} \\
\text { value }\end{array}$ & Under-weight & $\begin{array}{l}P \\
\text { value }\end{array}$ & Over-weight & $\begin{array}{l}\boldsymbol{P} \\
\text { value }\end{array}$ & Anemic & $\begin{array}{l}\boldsymbol{P} \\
\text { value }\end{array}$ & $\mathrm{N}$ \\
\hline & $\%$ & & $\%$ & & $\%$ & & $\%$ & & \\
\hline Dalit & 54.9 & $<0.001$ & 20.8 & $<0.001$ & 22.7 & $<0.001$ & 38.9 & $<0.001$ & 433 \\
\hline Muslim & 59.1 & & 31.3 & & 16.6 & & 52.3 & & 156 \\
\hline Janajati & 41.1 & & 10.6 & & 31.8 & & 35.5 & & 1023 \\
\hline Other terai caste & 59.7 & & 22.8 & & 14.9 & & 54.4 & & 495 \\
\hline Brahmin/Chhetri & 30.9 & & 9.8 & & 28.2 & & 36 & & 1016 \\
\hline Other & 47.3 & & 5.3 & & 49.8 & & 23.4 & & 170 \\
\hline \multicolumn{10}{|l|}{ Place of residence } \\
\hline Urban & 44.7 & 0.434 & 11.5 & $<0.001$ & 32.9 & $<0.001$ & 37.2 & 0.118 & 1978 \\
\hline Rural & 42.3 & & 18.4 & & 18.5 & & 41.9 & & 1315 \\
\hline \multicolumn{10}{|l|}{ Wealth quintile } \\
\hline Poorest & 36.2 & $<0.001$ & 17.1 & $<0.001$ & 11.3 & $<0.001$ & 28.1 & $<0.001$ & 578 \\
\hline Second poorest & 43.0 & & 18.0 & & 19.4 & & 37.8 & & 650 \\
\hline Middle & 49.8 & & 16.7 & & 15.2 & & 48.4 & & 698 \\
\hline Second richest & 49.7 & & 15.9 & & 30.2 & & 44.8 & & 707 \\
\hline Richest & 38.2 & & 3.7 & & 58.0 & & 34.0 & & 660 \\
\hline
\end{tabular}

shame and stigma, and social desirability bias [1, 17]. The tools used to measure domestic violence were developed and validated by WHO multi-country team and pre-tested in six countries (Bangladesh, Brazil, Namibia, Samoa, Thailand and the United Republic of Tanzania). The validation suggests that the instrument should provide reliable and valid measures for violence and is thus widely used in DHS globally. This tool, however, has not been validated in Nepal and thus may not accurately capture IPV experience and reporting in this context [18]. Furthermore, the NDHS module asks about IPV throughout one's life, whereas the nutritional measurement is at the time of the survey; thus, if the violence occurred at a much earlier point in life, it is reasonable to assume that it may not affect one's nutritional status as many factors throughout one's life combine to influence one's nutritional status at any given time. Finally, the lack of associations between IPV and nutritional status among Nepalese women could also be because in this context, IPV may not result in food being used as a control mechanism or that there is any relationship between suffering from IPV and being denied access to foods and services, which are important for nutritional well-being.

The association we found between controlling behaviors, but not other types of IPV, and anemia could suggest that controlling behaviors generate more prolonged psychological stress. This is a known risk factor for oxidative stress, which contributes to anemia [19]. We hypothesize, therefore, that chronic stress generated from experiencing controlling behaviors may be a reason these women were more at risk of being anemic [20]. The association found between physical violence and a decreased risk of overweight/obesity was consistent with the results of a cross-sectional population based study in Brazil which suggested that physical IPV was negatively associated with BMI [21]. On the other hand, some studies have found physical and non-physical IPV increased the risk of overweight/obesity of women [2224]. These divergent global findings suggest a need for further research.

Ackerson and Subramanian (2008) reported that domestic violence had a significant positive association with underweight and anemia among married women in India [4], yet their results showed that the associations were only significant for underweight when IPV experience has happened in the 12 months prior to the survey and for anemia only when IPV was experienced multiple times in the 12 months prior to the survey. They also found no significant association between underweight and anemia and violence experienced more than 1 year ago, which is similar to our measurement of ever experienced IPV. Another study conducted in Bangladesh, however, reported that women who had experienced IPV ever had 1.24 times greater odds of being underweight [3]. Although this is inconsistent with our findings, there are several reasons why comparison with this study is 


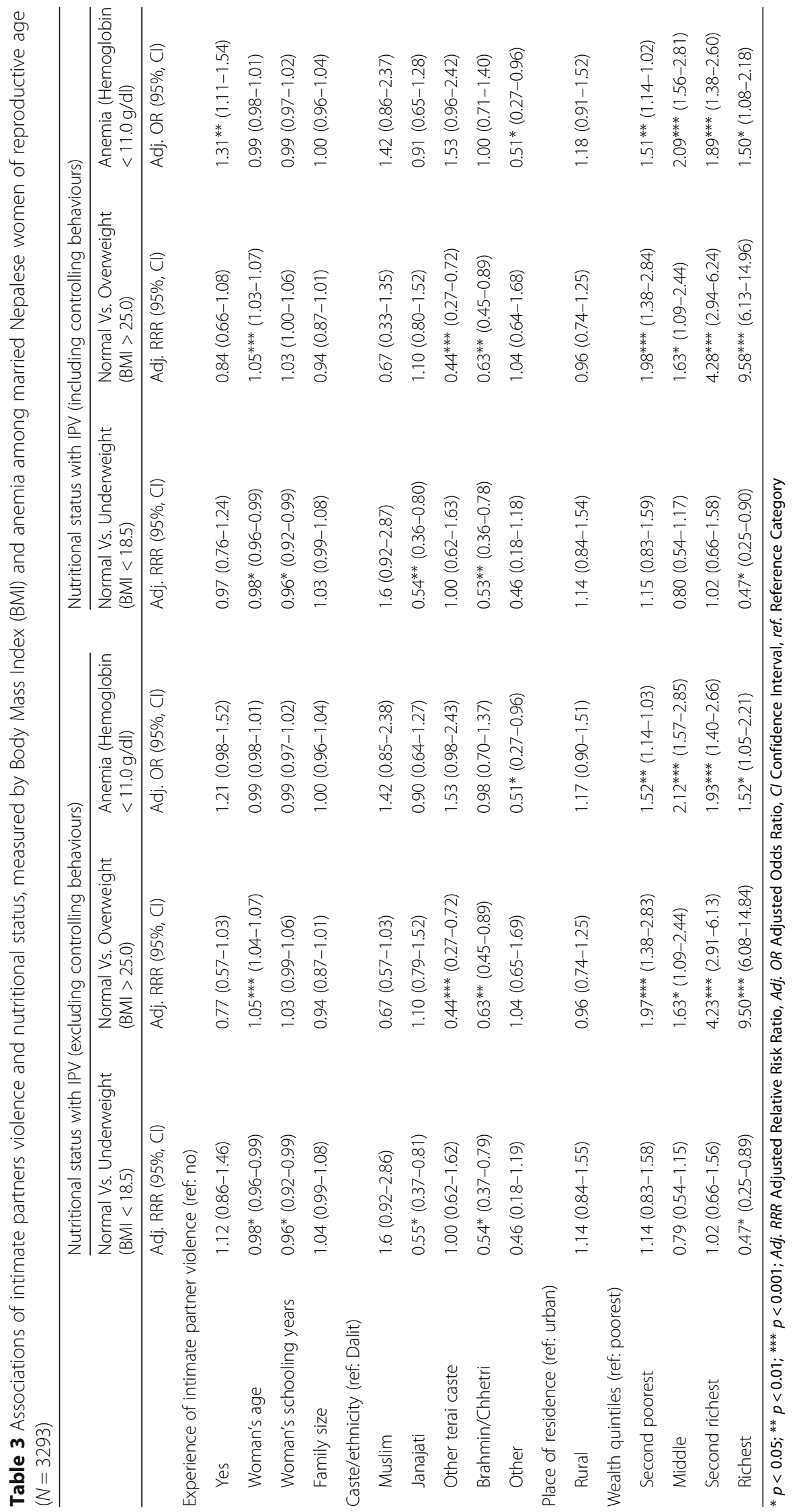




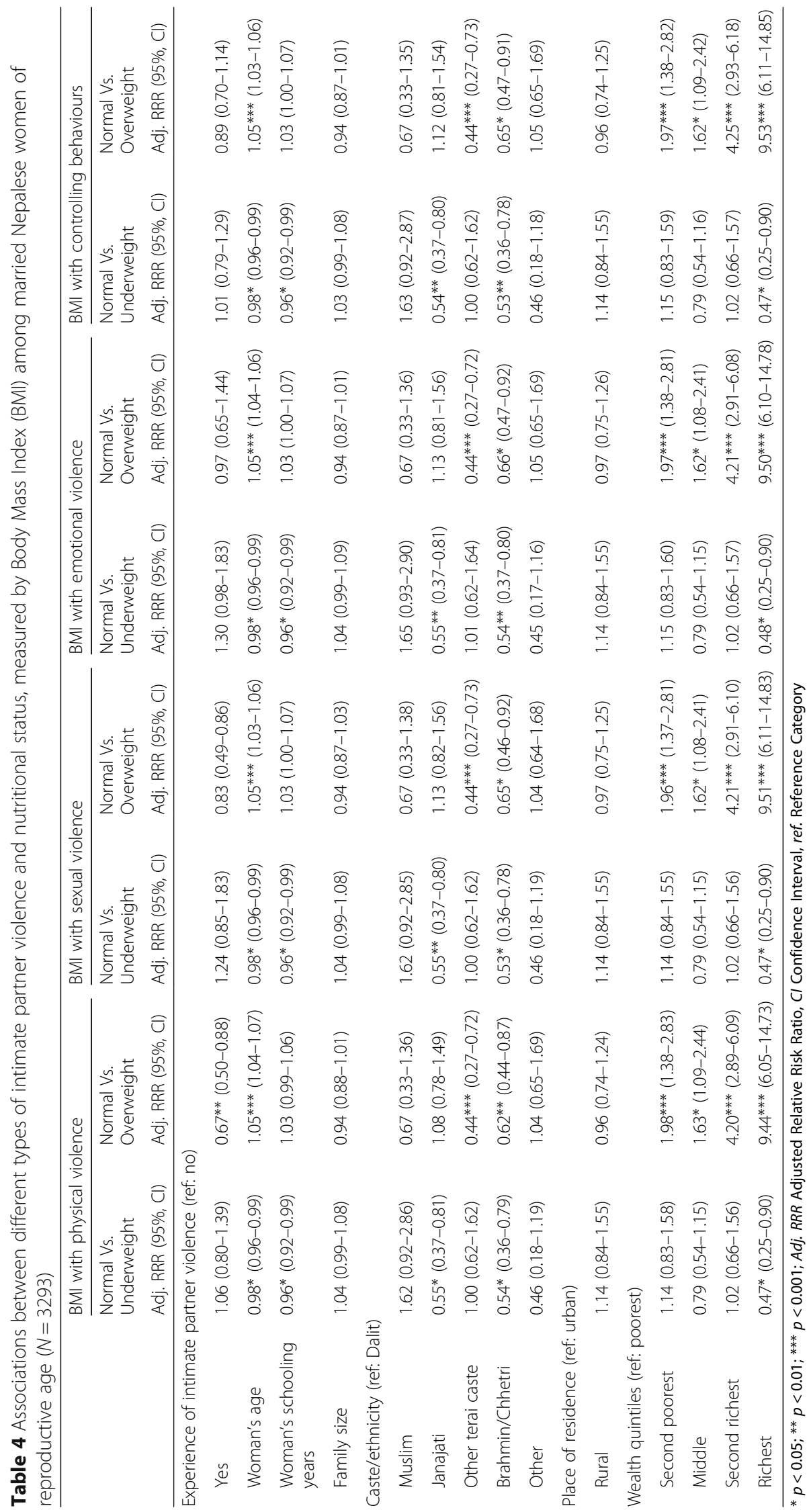




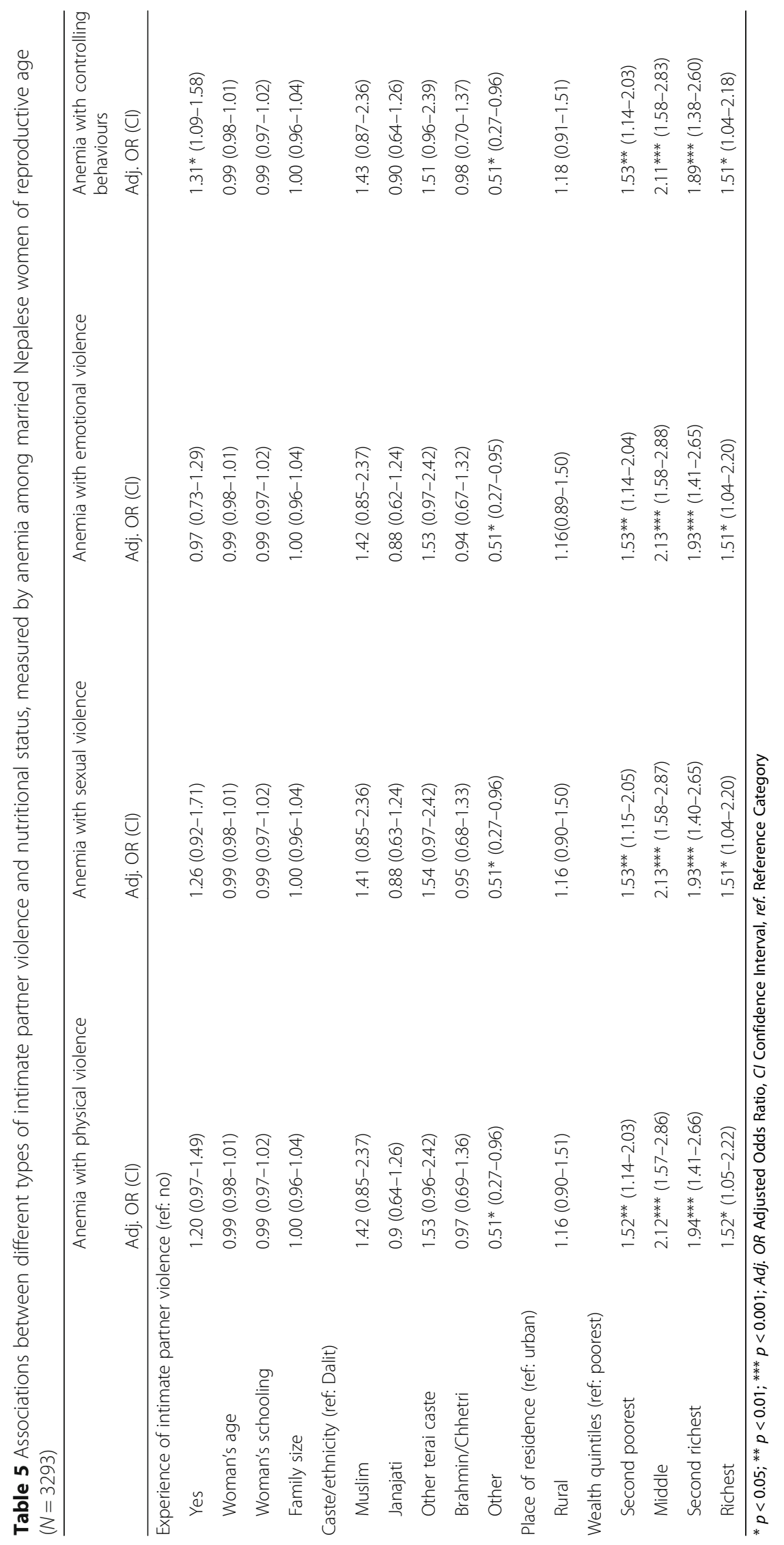


Table 6 Associations between severity of physical intimate partner violence and nutritional status, measured by Body Mass Index (BMI) and Anemia among married Nepalese women of reproductive age $(N=3293)$

\begin{tabular}{|c|c|c|c|}
\hline & Normal Vs. Underweight $(\mathrm{BMI}<18.5)$ & $\begin{array}{l}\text { Normal Vs. Overweight } \\
(\mathrm{BMI}>25.0)\end{array}$ & Anemia (Hemoglobin < 11.0 g/dl) \\
\hline & Adj. RRR $(95 \%, C l)$ & Adj. RRR $(95 \%, \mathrm{Cl})$ & Adj. OR $(95 \%, C l)$ \\
\hline \multicolumn{4}{|c|}{ Severity of physical violence (ref: no) } \\
\hline Moderate & $0.89(0.61-1.23)$ & $0.77(0.57-1.06)$ & $1.23(0.96-1.59)$ \\
\hline Severe & $1.29(0.89-1.86)$ & $0.53^{*}(0.32-0.88)$ & $1.17(0.86-1.58)$ \\
\hline Woman's age & $0.98^{*}(0.96-0.99)$ & $1.05^{* * *}(1.04-1.07)$ & $0.99(0.98-1.01)$ \\
\hline Woman's schooling & $0.96^{*}(0.92-0.99)$ & $1.03(0.99-1.06)$ & $0.99(0.97-1.02)$ \\
\hline Family size & $1.04(0.99-1.09)$ & $0.94(0.88-1.01)$ & $1.00(0.96-1.04)$ \\
\hline \multicolumn{4}{|l|}{ Caste/ethnicity (ref: Dalit) } \\
\hline Muslim & $1.62(0.92-2.85)$ & $0.68(0.33-1.39)$ & $1.42(0.85-2.37)$ \\
\hline Janajati & $0.55^{* *}(0.37-0.81)$ & $1.09(0.79-1.50)$ & $0.9(0.64-1.26)$ \\
\hline Other terai caste & $1.01(0.62-1.65)$ & $0.44^{* * *}(0.27-0.71)$ & $1.52(0.96-2.42)$ \\
\hline Brahmin/Chhetri & $0.54^{* *}(0.37-0.80)$ & $0.62^{* *}(0.44-0.87)$ & $0.97(0.69-1.36)$ \\
\hline Other & $0.46(0.18-1.19)$ & $1.06(0.65-1.72)$ & $0.51 *(0.27-0.95)$ \\
\hline \multicolumn{4}{|c|}{ Place of residence (ref: urban) } \\
\hline Rural & $1.13(0.84-1.54)$ & $0.96(0.74-1.24)$ & $1.17(0.90-1.51)$ \\
\hline \multicolumn{4}{|c|}{ Wealth quintile (ref: poorest) } \\
\hline Second poorest & $1.16(0.83-1.61)$ & $1.95^{* * *}(1.36-2.78)$ & $1.52^{* *}(1.14-2.03)$ \\
\hline Middle & $0.80(0.54-1.17)$ & $1.62^{*}(1.08-2.41)$ & $2.12^{* * *}(1.58-2.85)$ \\
\hline Second richest & $1.03(0.66-1.59)$ & $4.14^{* * *}(2.86-6.00)$ & $1.93^{* * *}(1.41-2.65)$ \\
\hline Richest & $0.48^{*}(0.25-0.91)$ & $9.39^{* * *}(6.02-14.63)$ & $1.52^{*}(1.05-2.21)$ \\
\hline
\end{tabular}

${ }^{*} p<0.05 ;{ }^{* *} p<0.01$; *** $p<0.001$; Adj. RRR Adjusted Relative Risk Ratio, Adj. OR Adjusted Odds Ratio, Cl Confidence Interval, ref. Reference Category

challenging. The prevalence of violence (53\% vs. 26\%) and underweight ( $28 \%$ vs $14 \%$ ) were both substantially greater in the Bangladesh study compared to our study, which may indicate that the study had greater power to detect a relationship. The Bangladesh study also only included physical violence and sexual violence, whereas we included physical, sexual and emotional violence in our definition of IPV. Finally, each study used slightly different confounders which may also explain differing results: wealth, for instance, was not adjusted for in the Bangladesh study and we found it to be a highly significant confounder in our analyses.

\section{Conclusion}

Our analyses were based on cross-sectional survey data, making causal assessment of the relationships between an individual experiencing IPV and her nutritional status impossible. Also because of the sensitivity and social stigma relating to IPV, there is a possibility of underreporting, especially when a module like this is integrated into a much longer health survey making in-depth rapport building needed to discuss sensitive topics more challenging. Despite these limitations, this study is unique in its assessment of the associations between the experience of IPV and women's nutritional status in Nepal, particularly looking at multiple indicators of malnutrition. The use of a nationally representative dataset is another study strength as it means the findings are generalizable at a population level. To the best of our knowledge, this is the first study to explore associations between a woman being exposed to IPV and her nutritional status in Nepal and only the third to do so ever using data from South Asia. Additional rigorous research using mixed methods is needed to understand the prevalence of IPV and why IPV is not associated with underweight, and overweight/obesity in this population, particularly given that it is associated in other South Asian contexts.

\section{Abbreviations}

BMI: Body Mass Index; Cl: Confidence Interval; DHS: Demographic and Health Survey; IPV: Intimate Partner Violence; LMICs: Low- and Middle- Income Countries; NDHS: Nepal Demographic and Health Survey; OR: Odds Ratio; ref.: Reference Category; RRR: Relative Risk Ratio; WRA: Women of Reproductive Age

\section{Acknowledgements}

We are thankful to the Demographic and Health Surveys (DHS) programme for providing the workshop opportunity to improve our data analysis skills and focus on the research questions in this paper. We would also like to thank Prof. Rolf Klemm, Johns Hopkins University and Helen Keller International, for reviewing the manuscript. Finally, we thank all of the survey 
team, especially the data collectors and supervisors who conducted the fieldwork, and the survey respondents for their time and energy.

\section{Authors' contributions}

RPA and KC designed the study. RPA analyzed data and prepared the first draft, AA, KC, SY revised the drafts. All authors reviewed multiple versions of the manuscript and read and approved the final version for submission.

\section{Funding}

This research is a product of the 2018 Subregional DHS Further Analysis Workshop funded by USAID and implemented by ICF, held in Pokhara, Nepal, 8-18 January 2018

\section{Availability of data and materials}

The datasets used in this study are available from the corresponding author based on request.

\section{Ethics approval and consent to participate}

The Nepal Demographic and Health Survey received ethical approval from the Nepal Health Research Council and ICF Institutional Review Board. This manuscript only involved secondary analyses of publicly available data so there was no need for separate ethical approval.

\section{Consent for publication}

Not applicable.

\section{Competing interests}

The authors declare that they have no competing interests.

\section{Author details}

'Suaahara II, Helen Keller International Nepal, Patan, Lalitpur, Nepal. ${ }^{2}$ Suaahara II, Care International, Lalitpur, Nepal. ${ }^{3}$ Suaahara II, FHI360, Kathmandu, Nepal. ${ }^{4}$ London School of Hygiene and Tropical Medicine, London, England.

Received: 25 September 2018 Accepted: 12 June 2020

Published online: 17 June 2020

\section{References}

1. WHO. Global and regional estimates of violence against women: prevalence and health effects of intimate partner violence and non-partner sexual violence: Geneva, World Health Organization; 2013.

2. Garcia-Moreno C, Jansen HA, Ellsberg M, Heise L, Watts CH. Prevalence of intimate partner violence: findings from the WHO multi-country study on women's health and domestic violence. Lancet. 2006:368:1260-9.

3. Rahman M, Nakamura K, Seino K, Kizuki M. Intimate partner violence and chronic undernutrition among married Bangladeshi women of reproductive age: are the poor uniquely disadvantaged? Eur J Clin Nutr. 2013;67:301-7.

4. Ackerson K, Subramanian SV. Domestic violence and chronic malnutrition among women and children in India. Am J Epidemiol. 2008;167(10):1188-96.

5. Naved RT, Persson LA. Factors associated with spousal physical violence against women in Bangladesh. Stud Fam Plan. 2005;36:289-300.

6. Bates LM, Schuler SR, Islam F, Islam K. Socioeconomic factors and processes associated with domestic violence in rural Bangladesh. Int Fam Plan Perspect. 2004:30:190-1.

7. Chai J, Fink G, Kaaya S, Danaei G, Fawzi W, Ezzati M, Fawzi MCS: Association between intimate partner violence and poor child growth: results from 42 demographic and health surveys Bull World Health Organ 2016, 94(5):331-339.

8. Ellsberg M, Jansen HA, Heise L, Watts CH, Garcia-Moreno C. Intimate partner violence and women's physical and mental health in the WHO multicountry study on women's health and domestic violence: an observational study. Lancet. 2008:371:1165-72.

9. Silverman JG, Gupta J, Decker MR, Kapur N, Raj A. Intimate partner violence and unwanted pregnancy, miscarriage, induced abortion, and stillbirth among a national sample of Bangladeshi women. BJOG. 2007;114:1246-52.

10. Campbell J, Jones AS, Dienemann J, Kub J, Schollenberger J, O'Campo P, Gielen AC, Wynne C. Intimate partner violence and physical health Consequnces. Arch Intern Med. 2002;162:1157-63.
11. Coker AL, Smith HP, Bethea L, King MJ, McKeown RE. Physical Health Consequences of Physical and Psychological Intimate Partner Violence. Arch Fam Med. 2000;9:451-7.

12. Lemon SC, Verhoek-Oftedahl W, Connelly EF. Preventive health care use smoking, and alcohol use among Rhode Island women experiencing intimate partner violence. J Womens Health Issues Gend Based Med. 2002; 11(6):555-62.

13. Diop-Sidibe N, Campbell JC, Becker S. Domestic violence against women in Egypt-- wife beating and health outcomes. Soc Sci Med. 2006;62(5):1260-77.

14. $\mathrm{MOH}$, New ERA, Inc. II: Nepal demographic and health survey 2016. Kathmandu: Ministry of Health, New ERA, and ICF International, Calverton, Maryland; 2016

15. Clark CJ, Ferguson G, Shrestha B, Shrestha PN, Oakes JM, Gupta J, Yount KM Social norms and women's risk of intimate partner violence in Nepal. Soc Sci Med. 2018:202:162-9.

16. UCL, CREHPA Tracking Cases of Gender-Based Violence in Nepal. Individual, institutional, legal and policy analyses. Kathmandu: University College London (UCL) and Centre for Research on Environment, Health and Population Activities (CREHPA); 2013.

17. Ghimire A, Samuels F. Understanding intimate partner violence in Nepal. Lalitpur: Overseas Development Institute and Nepal Institute for Social and Environmental Research; 2017.

18. WHO. WHO Multi-Country Study on Women's Health and Domestic Violence against Women: Summary Report of Initial Results on Prevalence, Health Outcomes and Women's Responses. Geneva: World Health Organization; 2005.

19. Yoo JH, Maeng HY, Sun YK, Kim YA, Park DW, Park TS, Lee ST, Choi JR. Oxidative status in iron-deficiency anemia. J Clin Lab Anal. 2009:23(5): 319-23.

20. Hassan ZA, Chelebi NA, BazzazandAA BS. Correlation of psychological stress to severity of anemia in Al-Haweeja women. Euro J Phar Med Res. 2016;3: 248-51.

21. Ferreira MF, CLd M, Reichenheim ME, Verly Junior E, Marques ES, SallesCosta R. Effect of physical intimate partner violence on body mass index in low-income adult women. Cad Saude Publica. 2015:31:161-72.

22. Davies R, Lehman E, Perry A, McCall-Hosenfeld JS. Association of intimate partner violence and health-care provider-identified obesity. Women Health. 2016;56(5):561-75

23. Mason SM, Ayour N, Canney S, Eisenberg ME, Neumark-Sztainer D. Intimate partner violence and 5-year weight change in young women: a longitudinal study. J Women's Health. 2017;26(6):677-82.

24. Ferdos J, Rahman M. Exposure to intimate partner violence and malnutrition among young adult Bangladeshi women: cross-sectional study of a nationally representative sample. Cad Saude Publica. 2018;34: e00113916

\section{Publisher's Note}

Springer Nature remains neutral with regard to jurisdictional claims in published maps and institutional affiliations.
Ready to submit your research? Choose BMC and benefit from:

- fast, convenient online submission

- thorough peer review by experienced researchers in your field

- rapid publication on acceptance

- support for research data, including large and complex data types

- gold Open Access which fosters wider collaboration and increased citations

- maximum visibility for your research: over $100 \mathrm{M}$ website views per year

At BMC, research is always in progress.

Learn more biomedcentral.com/submissions 